\title{
Underexpanded Jet-Freestream Interactions on an Axisymmetric Afterbody Configuration
}

\author{
N. B. Mathur* and K. S. Yajnik* \\ National Aeronautical Laboratory, Bangalore, India
}

\begin{abstract}
Experimental investigations are carried out in the $0.3 \mathrm{~m}$ trisonic wind tunnel at NAL to study exhaust jetfreestream interactions on an axisymmetric afterbody configuration. The model chosen for these studies is an equivalent body of revolution of a representative combat aircraft configuration. The effects of jet pressure ratio and freestream Mach number on boattail, base, and afterbody pressure drag are studied along with color Schlieren flow visualization of the afterbody flowfield. Experiments are carried out in the freestream Mach number range of 0.6 to 1.1 at Reynolds number from $20 \times 10^{6} / \mathrm{m}$ to $35 \times 10^{6} / \mathrm{m}$ keeping model at zero degree of incidence. Jet pressure ratio is varied from 1 to 6 during this investigation. The jet at nozzle exit is sonic throughout these tests. Experimental results show that the underexpanded jet plume affects predominantly the afterbody pressure distribution and hence the afterbody pressure drag. Upstream influence of the jet extends even up to the boattail shoulder and is predominant in the region of freestream shock location over the afterbody at transonic speeds. The movement of shock location determined from color Schlieren flow visualization studies agree well with the theoretical predictions made on the basis of transonic small perturbation calculations.
\end{abstract}

\section{Nomenclature}

$=$ afterbody

$=$ base

$=$ jet

$=$ freestream

$=$ shock, separation

= boattail

\section{Introduction}

$F^{\circ}$ LOW interactions taking place near the aft end of an aerospace vehicle in presence of jets can have important repercussions on its performance. In particular, afterbody drag characteristic is greatly influenced by jet plume blockage and entrainment, which depends largely on velocity and temperature gradients existing between the jet and external flow. ${ }^{1-3}$ For example, afterbody/nozzle drag in a typical figher aircraft may be as large as $20 \%$ of the total aircraft drag at transonic speeds. ${ }^{4}$ In the case of a missile, the base drag may be as large as $70 \%$ of the total drag at transonic speeds. Systematic and extensive wind-tunnel testing is required to

Received Sept. 25, 1987; revision received Aug. 10, 1988. Copyright (C) 1989 American Institute of Aeronautics and Astronautics, Inc. All rights reserved.

*Scientist, Fluid Mechanics Division. study these aft end interactions, which are generally quite complex..$^{6-8}$

Several experimental studies on jet effects have been reported in the literature. For example, experimental investigations of Reubush et al..$^{9}$ at NASA, Zonars et al..$^{10}$ at AFFDL, Dissen et al. ${ }^{11}$ at DFVLR, and others are generally limited to the determination of pressure distribution and drag characteristics of the afterbodies. Also, the base drag of the annular base region of the afterbody is often neglected in most of these investigations, and its behavior in presence of a jet is not generally studied. Moreover, most of these studies are not supplemented by flow visualization studies, which prevents understanding of the behavior of flow over the boattailed afterbody as well as nozzle-exit region, particularly at transonic speeds. The present investigation was undertaken to study the effects of underexpanded sonic jet-freestream interactions on an axisymmetric boattailed afterbody configuration, systematically varying freestream Mach number and jet pressure ratio. Color Schlieren flow-visualization studies were also carried out to facilitate understanding of the behavior of the flow (particularly the shocks and their movement over the afterbody) with and without an underexpanded sonic jet.

\section{Model and Test Conditions}

The model (Fig. 1), $0.372 \mathrm{~m}$ long, is an equivalent body of revolution of a representative combat aircraft configuration. The model afterbody was designed to have a convergent nozzle with exit diameter of $0.0145 \mathrm{~m}$. The model was mounted on the side wall of the wind tunnel with the help of a hallow strut. ${ }^{12}$

Experiments were conducted in the freestream Mach number range of 0.6 to 1.1 at Reynolds number from $20 \times 10^{6} / \mathrm{m}$ to $35 \times 10^{6} / \mathrm{m}$. The jet pressure ratio was varied from 1 (jet-off) to about 6 , keeping the model at zero degree of incidence during this investigation.

\section{Afterbody Test Rig}

A test rig (Fig. 2) was designed and fabricated especially for conducting afterbody/base flow studies for configurations of various aerospace vehicles in presence of jets in the $0.3 \mathrm{~m}$ trisonic wind tunnel. Special design features of the rig are a) interchangeability for axisymmetric configurations and nonaxisymmetric shapes of realistic aircraft configurations and b) easier changing of various afterbody/nozzle geometries. The 


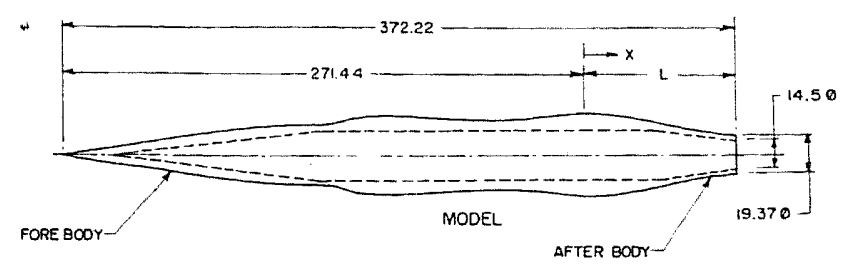

ALL DIMENSIONS IN M.M. NOT TO SCALE

Fig. 1 Axisymmetric model.

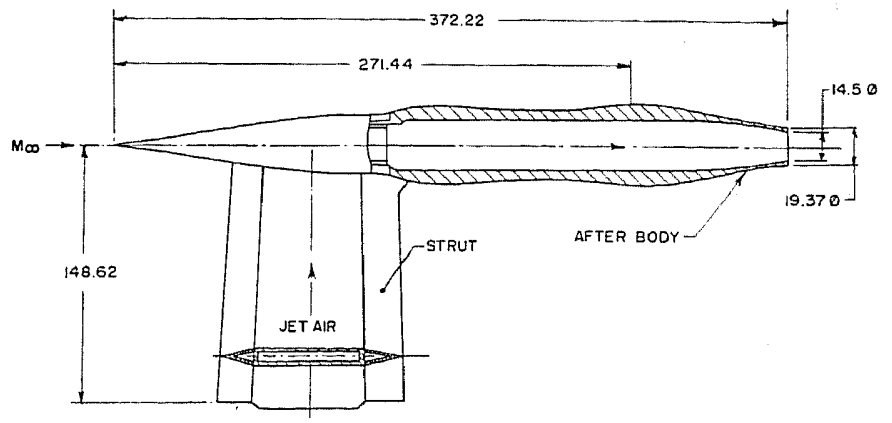

Fig. 2 Afterbody teșt rig.

model is mounted to the side wall of the wind tunnel with the help of a hollow strut (Fig. 2). The strut not only supports the model at the centerline of $0.3 \mathrm{~m}$ trisonic wind tunnel, but also acts as a duct for supplying the high pressure compressed air jet required during jet-on experiments. The strut has two hollow, V-shaped wedges, one on either side, to accommodate the pressure tubings/balance cables, etc. A Schlieren glass with its frame is specially designed and mounted so that it provides the visualization of flowfield around the afterbody-nozzle-exit region, particularly at the transonic speeds of this investigation. Jet pressure ratios ranging from 1 to 10 (maximum pressure of available compressed air is $10.55 \mathrm{Kg} / \mathrm{cms}^{2}$ ) can be achieved during experiments. This range of jet pressure ratio simulates the wide range of nozzle operation of combat aircrafts.

\section{Instrumentation and Measurements}

Longitudinal static pressure distribution on the afterbody and base pressures were obtained in presence of a cold sonic jet and also for jet-off conditions by using a 48 ports scanivalve that houses a $\pm 34.5 \mathrm{kN} / \mathrm{m}^{2}$ Statham pressure transducer. The pressure tubings were connected to the scanivalve through hollow wedges of the strut. The establishment of freestream flow and also the jet flow through a nozzle during the tunnel run was checked from the online record of pressure data recorded on the strip chart recorder. Model pressures were trapped after both flows were established and were scanned immediately after the tunnel run was over. $C p$ distribution so obtained is expected to be accurate to \pm 0.003 . Jet stagnation pressure was measured using a $1379 \mathrm{kN} / \mathrm{m}^{2}$ $C E C$ pressure transducer. Longitudinal static pressure distribution on the afterbody is numerically integrated to obtain afterbody pressure drag coefficient $C_{D P}$, which represents here the boattail pressure drag plus base pressure drag coefficient. Measurements include surface pressures on the boattail afterbody, pressures in the annular base region, static and stagnation pressure of jet and freestream, surface oil flow patterns, and color Schlieren flow visualization.

\section{Results and Discussion}

Figure 3 shows a typical longitudinal static pressure distribution on the afterbody and also the corresponding Schlieren
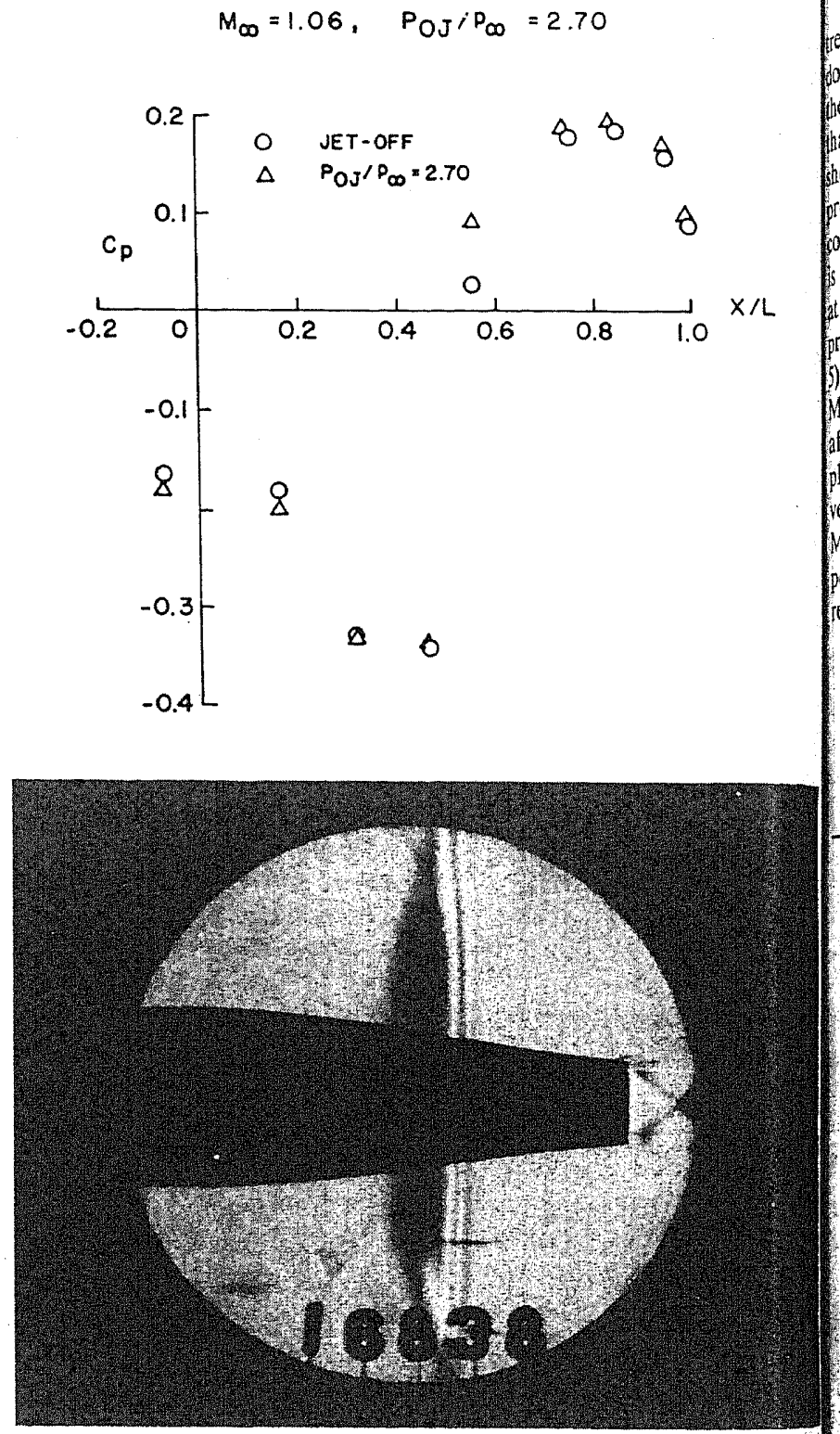

Fig. 3 Longitudinal static pressure distribution on afterbody and Schlieren photograph at $M_{\infty}=1.06$.

photograph of the flow in the presence of a jet. The stat pressure around the afterbody shoulder can be seen to do crease due to flow expansion until a peak (negative) is reached and beyond that the boattail static pressure is seen to increase due to recompression downstream of the boattail shoulder 0 the afterbody. The decrease in static pressures around th boattail-end region is because of flow expansion caused by the typical shape of the afterbody, which had inward curvature The effect of the underexpanded jet is noticeable (Fig. 3) eve up to upstream of the boattail shoulder (near $X / L=-0.1$ ) causing a change in static pressure with respect to jet-off $\cos$ dition. A sharp increase in statice pressure (between $X / L=0$. and 0.6 ) over the boattail indicates the presence of shock ( $\mathrm{rel}$ color region in the Schlieren photograph). A relatively larg increase in static pressure in the region of shock location (ne2 $X / L=0.6$ ) in the presence of the underexpanded jet indicate a predominant jet plume effect over the boattail upstream 0 nozzle exit. The displacement effect of the underexpanded jo seems to strengthen the freestream shock ${ }^{13}$ over the boattal causing a larger increase in static pressure in the region 0 shock location compared to that of jet-off condition. A colot Schlieren photograph of the flow was taken with the knit edge at the green color gelantine-based filter. The thick If color region over the afterbody shows the compression fart: whereas the red-yellow mixed region shows the presence of $x$ 
treme density gradients near the shock front. The blue region downstream of the nozzle exit plane shows the expansion of the underexpanded jet terminated by jet shocks (red color) that get reflected near the axis of the jet. Yellow curved lines show the jet boundary. Figures 4 and 5 show the effect of jet pressure ratio on base pressure and afterbody pressure drag coefficient. Results show that the entrainment effect of the jet is predominant for lower freestream Mach number $\left(M_{\infty} \leq 0.8\right)$ at low jet pressure ratios $(\leq 3)$, as seen by the decrease in base pressure (Fig. 4) and increase in afterbody pressure drag (Fig. 5 ) in this range of flow conditions. For higher freestream Mach numbers $\left(M_{\infty}>0.8\right)$, the base pressure increases and afterbody pressure drag decreases, indicating a favorable jet plume effect throughout the jet pressure ratio range of this investigation. It can also be noted that at higher freestream Mach numbers, i.e., $M_{\infty}=0.99$ and 1.06 , the base pressure is positive, which indicates a pressure thrust on the annular base region of the afterbody. The increase in base pressure thrust
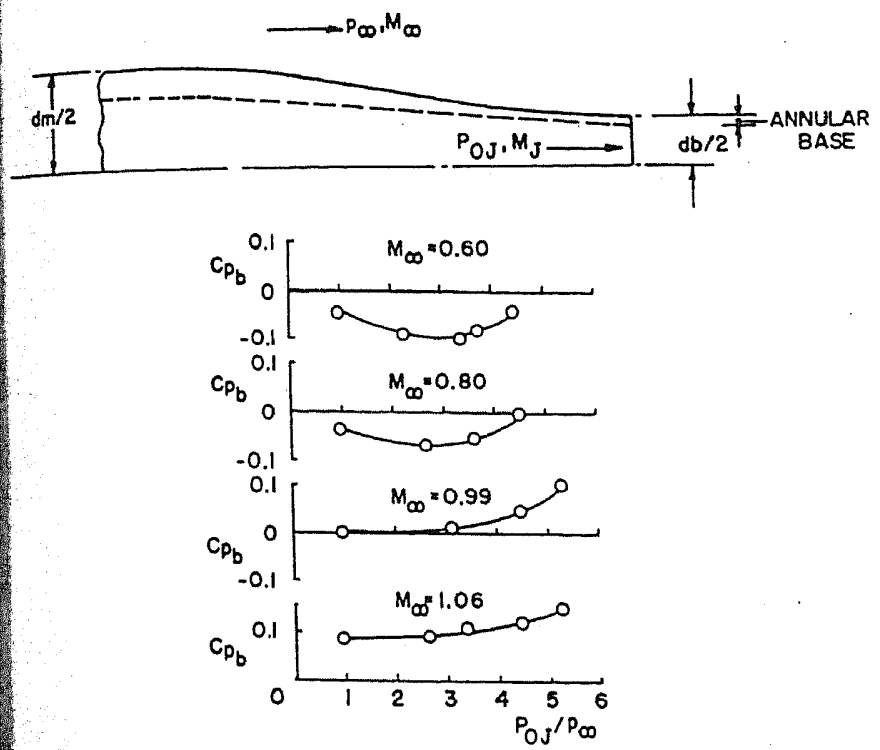

Fig. 4 Variation of base pressure coefficient with jet pressure ratio.

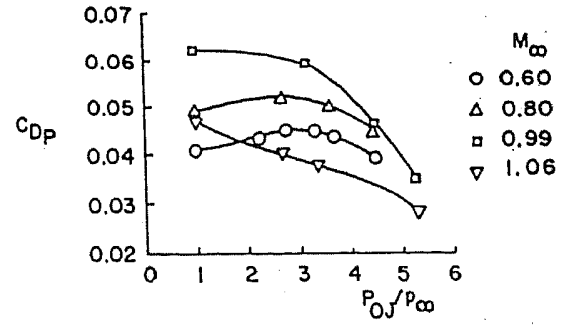

Fig. 5 Variation of afterbody drag coefficient with jet pressure ratio.

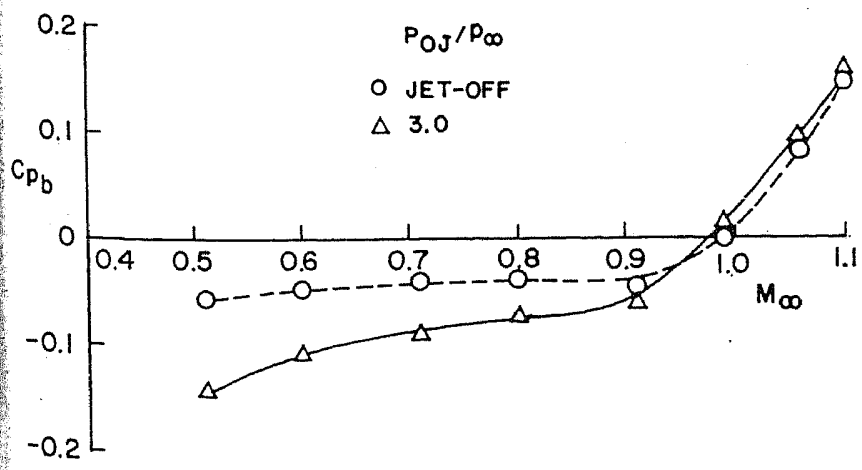

fart Fig. 6 Variation of base pressure with freestream Mach number of exh (with and without jet). with increase in jet pressure ratio causes a net decrease in the afterbody pressure drag (Fig. 5) throughout the jet pressure ratio range of this investigation.

As the freestream Mach number is increased from subsonic to transonic Mach number range, i.e., at $M_{\infty}=0.99$, jet-off condition, there is a comparatively large increase in afterbody pressure drag (transonic drag rise), and this value is considerably higher (Fig. 5) than the drag values at subsonic freestream Mach numbers (i.e., $M_{\infty}=0.6$ and 0.8). Hence, at $M_{\infty}=0.99$, when the jet pressure ratio is increased from jet-off condition, afterbody pressure drag decreased proportional to base pressure levels (Fig. 4) at various jet pressure ratios. Hence, although there is a continuous decrease of $C_{D P}$ due to increase in base pressure thrust, the drag values decreased from a higher initial value to the extent that it remained higher than the corresponding drag values at subsonic freestream Mach numbers until the jet plume displacement effect became predominant at jet pressure ratio of about 5.3 .

When the freestream Mach number crosses the sonic condition, the entrainment effect of the jet diminished (due to negligible difference in velocities between the freestream and sonic jet), and the jet displacement effect became predominant, causing increase in base pressure (Fig. 4) and decrease in afterbody pressure drag (Fig. 5) with the increase in jet pressure ratio. Also, as the freestream Mach number is increased from 0.99 to 1.06 at jet-off condition, the freestream shock moved downstream (Fig. 7a), altering the afterbody pressure distribution such that expansion region is reduced and level of static pressures in the recompression region increased, decreasing the afterbody pressure drag. Again at $M_{\infty}=1.06$, as the jet pressure is increased from jet-off conditions, base pressures increased (increasing base pressure thrust), causing a further decrease in afterbody pressure drag.

Figure 6 shows the effect of freestream Mach number on base pressure with and without the presence of a jet. Results show again that the entrainment effect of jet that is predomi-

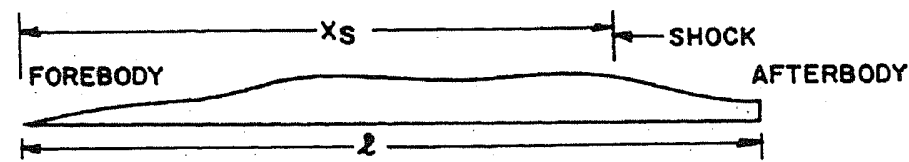

O EXPERIMENTS - MATHUR
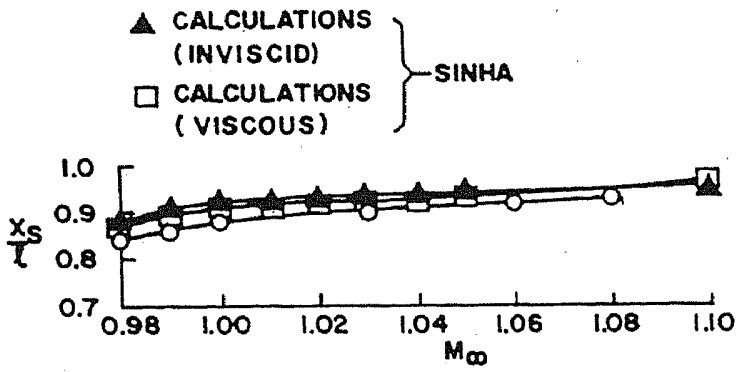

Fig. 7a Shock location on axisymmetric afterbody: comparison between experiments (NAL-FM) and calculations (NAL-FM).

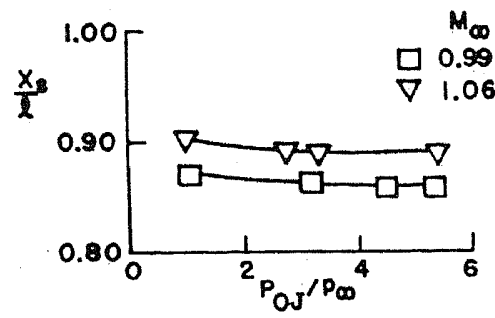

Fig. 7b Variation of freestream shock location on afterbody with jet pressure ratio. 
nant for the freestream Mach number less than that of jet stream Mach number (i.e., 1.0) caused the decrease in base pressures (with respect to jet-off condition) and this effect diminished as the freestream Mach number approached the jet stream Mach number.

The movement of freestream shock location on the afterbody (determined from schlieren photographs) for jet-off case show (Fig. 7a) a trend similar to theoretical predictions made at NAL on the basis of transonic small perturbation calculations. ${ }^{14}$

As the freestream Mach number in the transonic range increases, supersonic region ahead of the freestream shock increases and the freestream shock moves downstream (Fig. 7a), due to decrease in stagnation pressure downstream of the shock. (With the increase in Mach number ahead of the shock, the stagnation pressure downstream of the shock decreases.)

The underexpanded jet plume affects predominantly the flow over the afterbody, causing the freestream shock (location determined from Schlieren photographs) to move upstream of the nozzle exit, as indicated by the decrease in $x_{s} / \ell$ with the increase in jet pressure ratio (Fig. $7 \mathrm{~b}$ ). Upstream movement of the freestream shock is maximized when the jet pressure ratio is increased from 1 (jet-off) to about 3 as observed during this investigation. Beyond a jet pressure ratio of about 3 , there is no noticeable freestream shock movement over the afterbody, but the displacement effect of underexpanded jet continues to cause a favorable effect, decreasing the afterbody pressure drag (Fig. 5).

\section{Conclusions}

Underexpanded jet plume affects predominantly on the afterbody pressure distribution and hence afterbody pressure drag.

Upstream influence of the jet extends even up to a boattail shoulder and is predominant in the region of freestream shock location over the afterbody.

Entrainment effect of the jet is predominant for lower freestream Mach numbers $(\leq 0.8)$ at low jet pressure ratios $(\leq 3.0)$, while the displacement effect of the jet is predominant at higher freestream Mach number $(>0.8)$ and higher jet pressure ratios $(>3.0)$. At higher freestream Mach number $(>0.8)$, the displacement effect of the jet continues to be predominant throughout the jet pressure ratio range of this investigation.

\section{Acknowledgments}

The authors are very thankful to U. N. Sinha, Head, Aerodynamics Division, for his help in carrying out theoretical calculations, and K. Krishnamurthy, in charge of the $0.3 \mathrm{~m}$ trisonic wind tunnel, for providing assistance in carrying out these experiments in the wind tunnel. The authors also ac. knowledge the model shop staff for fabricating the model with its support system and the staff of the $0.3 \mathrm{~m}$ trisonic wind tunnel for its help in conducting the experiments.

\section{References}

${ }^{1}$ Mathur, N. B. and Yajnik, K. S., "Jet Plume Temperature Ef fects on Afterbody Pressure Distribution and Drag," International Journal of Turbo and Jet Engines, Vol. 3, No. 1, 1986, pp. 91-97.

${ }^{2}$ Mathur, N. B., "Effects of Under-Expanded Jet on Afterbody of an Axisymmetric Configuration," NAL FM-TM-84-2, Feb. 1984.

${ }^{3}$ Bergman, D., "Effects of Engine Exhaust Flow on Boattail Drag," Journal of Aircraft, Vol. 18, June 1971.

${ }^{4}$ Midgal, D., Miller, E. H., and Schnell, U. C., "An Experimental Evaluation of Exhaust Nozzle/Airframe Interference," AIAA Paper 69-430, 1969.

${ }^{5}$ Delery, J. and Sirieix, M., "Base Flows Behind Missiles," ONERA TP 1979-14E, 1979.

${ }_{6}^{6}$ Jaarsma, F., "Experimental Determination of Nozzle Characteristics and Nozzle Airframe Interference," AGARD-LS-53, Paper 5 May 1972.

${ }^{7}$ Compton, W., B., III, "An Experimental Study of Jet Exhaust Simulation," AGARD-CP-150, Paper 16, March 1975.

${ }^{8}$ Zacharias, A., "An Experimental and Theoretical Investigation of the Interaction Between the Engine Jet and Surrounding Flow Field with Regard to the Pressure Drag on Afterbodies," AGARD-CP-308, Paper 8, Jan. 1982.

${ }^{9}$ Reubush, D. E. and Runckel, J. F., "Effects of Fineness Ratio on Boattail Drag of Circular Arc Afterbodies Having Closure Ratios of 0.5 with Jet Exhaust at Mach Numbers Up to 1.30," NASA TN D. 7192, May 1973.

${ }^{10}$ Zonars, D., Laughery, J. A., and Bowers, D. L., "Effects of Varying Reynolds Number and Boundary Layẹ Displacement Thick ness on the External Flow Over Nozzle Boattails," AGARD-AG-208, Paper 1-F, Oct. 1975.

${ }^{11}$ Dissen, H., Emunds, H., Riedel, H., and Zacharias, A., "Influence of Jet Parameters: Boattail Pressure Distribution and Pressur Drag," AGARD-AG-208, Paper II.D, Oct. 1975.

${ }^{12}$ Mathur, N. B. and Ramakrishna, M. S., "A Rig for Testing Afterbodies of Aerospace Vehicles in Presence of Jet in $0.3 \mathrm{~m}$ Trisonic Wind Tunnel,"' NAL FM-TM-84-7, Aug. 1984.

${ }^{13}$ Wu, J. M., Moulden, T. H., Venghaus, H. H., Spring, D. J., and Henderson, J. H., "Plume Induced Separation from a Single Nozzle Exhaust at Transonic Flight Speed," Proceedings of the 7th JANNAF Plume Technology Meeting, 1973, pp. 577-597.

${ }^{14}$ Sinha, U. N. and Sarasamma, V. R., "Calculation of Axisymmetric Transonic Small Perturbation Equation Using Conservative Scheme," NAL FM-TM-84-1, Jan. 1984. 